\title{
FORMULATION AND EVALUATION OF BUCCOADHESIVE TABLETS OF BUSPIRONE HYDROCHLORIC ACID
}

\author{
JIGNYASA RAVAL ${ }^{1}$, ANKITA YAGNIK ${ }^{2 *}$ \\ ${ }^{1}$ Department of Industrial Pharmacy, Shree S.K. Patel College of Pharmaceutical Education and Research, Ganpat University, \\ Mehsana, Gujarat, India. ${ }^{2}$ Department of Pharmaceutics, Akshar-Preet Institute of Pharmacy, Jamnagar, Gujarat, India. \\ Email: yagnikankita.07@gmail.com
}

Received: 28 August 2019, Revised and Accepted: 29 October 2020

ABSTRACT

Objective: The aim of the study was to prepare and evaluate buccal-adhesive tablets of buspirone hydrochloric acid (HCl) that avoids gastric degradation and first-pass metabolism, thereby increasing the drug bioavailability and onset of action. Buspirone HCl belongs to a class anxiolytic agent and a serotonin receptor agonist belonging to the azaspirodecanedione class of compounds.

Methods: In the present work, different ratios of Gantrez MS 955 along with Carbopol 934 were studied to give bioadhesive strength. A $3^{2}$ full factorial design was applied to investigate the combined effect of Gantrez MS 955 concentration (X1) and Carbopol 934 concentration (X2).

Results: Results of the multiple regression analysis revealed that the independent variables significantly affected the dependent variables (bioadhesive strength [Y1], Q2 [Y2], Q3 [Y3], Q4 [Y4]). On the basis of multiple linear regression analysis and contour plot evaluation, it was found that the combination of two polymers possessed excellent mucoadhesive properties allowing ease of application and removal of the tablets from the buccal mucosa.

Conclusion: The formulation batch A9 fulfilled all the criteria set from the desirability search. From the in vitro diffusion study, flux was calculated for the optimized batch. A study of the effect of tablet diameter and the environmental factors on the bioadhesion of the tablet was done. To study the environmental factor on bioadhesion, prehydration time and contact time were considered. Results found that increase in prehydration time decrease in bioadhesive strength and increase in contact time increased bioadhesive strength. Thus, a stable buccoadhesive formulation optimized for formulation ingredients and process parameters was prepared successfully.

Keywords: Buccal adhesive tablets, Buspirone hydrochloric acid, Anti-Anxiety, Anxiolytic agent, Gantrez MS 955, Carbopol 934, Buccoadhesive tablet. (C) 2021 The Authors. Published by Innovare Academic Sciences Pvt Ltd. This is an open access article under the CC BY license (http://creativecommons.org/ licenses/by/4.0/) DOI: http://dx.doi.org/10.22159/ajpcr.2021v14i1.39567. Journal homepage: https://innovareacademics.in/journals/index.php/ajpcr

\section{INTRODUCTION}

Buccal mucosa is an attractive route for systemic delivery of drugs as it is relatively permeable with a rich blood supply. Moreover, it has high robustness and accessibility. A drug can be easily applied and localized at the application site and can also be removed from there if necessary [1-3]. The buccal mucosa has been investigated for local and systemic delivery of therapeutic peptides and other drugs that are subjected to the firstpass metabolism or are unstable within the rest of the gastrointestinal tract. Buccal delivery for the transmucosal absorption of drugs into the systemic circulation offers a number of advantages over oral delivery, especially for those drugs that have poor oral bioavailability and/or those drugs that suffer from extensive first-pass metabolism in the liver. Conceivably, buccal delivery systems provide ease of administration and thereby increase patient compliance [4-6]. Buspirone hydrochloric acid $(\mathrm{HCl})$ is an anxiolytic agent and a serotonin receptor agonist belonging to the azaspirodecanedione class of compounds. It is used in the treatment of generalized anxiety, where it has advantages over other anti-anxiety drugs because it does not cause sedation (drowsiness) and does not cause tolerance or physical dependence. Buspirone hydrochloride binds to 5-HT type $1 \mathrm{~A}$ serotonin receptors on presynaptic neurons in the dorsal raphe and on postsynaptic neurons in the hippocampus, thus inhibiting the firing rate of 5-HT-containing neurons in the dorsal raphe. Buspirone also binds at dopamine (DA) type 2 receptors, blocking presynaptic DA receptors. It increases firing in the locus ceruleus, an area of brain where norepinephrine cell bodies are found in high concentration. The net result of buspirone actions is that serotonergic activity is suppressed while noradrenergic and dopaminergic cell firing is enhanced $[7,8]$. In this study, an attempt has been made to develop buspirone hydrochloride buccal adhesive tablet to avoid first-pass metabolism and increase the bioavailability of the drug. There are two prime considerations in the design of buccal adhesive tablet of Buspirone $\mathrm{HCl}$, One is to attach firmly to the buccal mucosa and other in case of buspirone hydrochloride the extensive first-pass metabolism. There are various bioadhesive polymers present which are polyacrylic acid derivatives such as polycarbophil and other polymers such as sodium alginate, Chitosan, HPC, HEC, sodium carboxymethylcellulose, polyethylene oxide, and hydroxypropyl methylcellulose (HPMC). In the present work, Gantrez MS 955 and Carbopol 934 were selected for the adhesive dosage form. Carbopol 934 (carbomers) is polyacrylic acid and Gantrez MS 955 is polyacrylic acid derivative, having both anion and cation $[9,10]$.

\section{METHODS}

Buspirone $\mathrm{HCl}$ was obtained as a gift sample from Astron Pharmaceuticals, Ahmedabad, India. Gantrez MS 955 was obtained from ISP India Ltd., India. Carbopol 934, HPMC K4M, HPMC K15M, sodium alginate, sodium carboxymethylcellulose, microcrystalline cellulose, mannitol, lactose, magnesium stearate, and talc were purchased from S.D. Fine Chemicals Ltd., Mumbai, India. Ethylcellulose was purchased from Asha Cellulose Pvt. Ltd., Valsad, India, all ingredients were of analytical grade.

Work was carried out during M. Pharm project in 2013-2014 at S. K. Patel College of Pharmaceutical Education and Research, Kherva.

\section{Preformulation Study}

Pre-formulation studies to generate supportive data were performed to understand the physicochemical behavior of a drug and the necessary 
modifications needed to design, develop, and evaluate dosage forms. The preformulation studies performed were:

1. Ultraviolet (UV). spectroscopy of buspirone $\mathrm{HCl}$

2. DSC [11-13]

3. Excipient compatibility with the drug using Fourier-transform infrared (FTIR) [14-20].

Results are discussed in result and discussion.

\section{Formulation of buccal tablets}

Bilayered tablets of a backing layer and adhesive drug reservoir layer were prepared by covering one side of a single-layer tablet with a layer of ethylcellulose. Ethylcellulose was selected as a hydrophobic polymer that has very low water permeability, thus providing an impermeable backing layer that can prevent drug loss in the oral cavity.

Drug containing layer of the tablets was prepared by direct compression of drug blended with Carbopol-934, Gantrez MS-955, and other excipients using $8 \mathrm{~mm}$ flat-faced punches at a lower hardness then the backing layer of ethyl cellulose was compressed with a final hardness to obtain the final Bilayered tablets [21].

\section{Experimental Design}

On the basis of the preliminary trials, a $3^{2}$ full factorial design was employed to study the effect of independent variables, that is, amount of Carbopol-934 (X1) and the amount of Gantrez MS-955 (X2), in terms of ratio against 1 part of drug on dependent variables such as bioadhesion strength (Y1) and \% drug release Q2 (Y2), Q4 (Y3), and Q6 (Y4). A statistical model (equation below) incorporating interactive and polynomial terms was utilized to evaluate the responses.

\section{$\mathrm{Y}=\mathrm{b} 0+\mathrm{b} 1 \mathrm{X} 1+\mathrm{b} 2 \mathrm{X} 2+\mathrm{b} 12 \mathrm{X} 1 \mathrm{X} 2+\mathrm{b} 11 \mathrm{X} 12+\mathrm{b} 22 \mathrm{X} 22$}

Where, $\mathrm{Y}$ is the dependent variable

b0 is the arithmetic mean response of the nine runs

b1 is the estimated coefficient for the factor X1

The main effects (X1 and $\mathrm{X} 2$ ) represent the average result of changing one factor at a time from its low to high value. The interaction terms (X1X2) show how the response changes when two factors are simultaneously changed. The polynomial terms (X12 and X22) are included to investigate non-linearity. The design matrix for the experiment is shown in Table 2.

\section{Evaluation of buccoadhesive tablets}

In-vitro dissolution study

Drug release was studied using the USP XIII dissolution test apparatus using a rotating basket at $37 \pm 0.5^{\circ} \mathrm{C}$ at $100 \mathrm{rpm}$. Tablet was added to $900 \mathrm{ml}$ of phosphate buffer of $6.4 \mathrm{pH}$. The backing layer of buccal tablet was attached to the vessel with instant adhesive (cyanoacrylate adhesive). Samples were withdrawn at specified time intervals and replaced with fresh dissolution medium (phosphate buffer $\mathrm{pH}$ 6.4). The amount of drug released was determined spectrophotometrically at $239 \mathrm{~nm}$. The release rate study was carried out for $6 \mathrm{~h}$. Cumulative percentage of drug release was calculated using the equation obtained from the standard curve. The drug in phosphate buffer ( $\mathrm{pH}$ 6.4) followed Beer Lambert's law in the range of $0-12 \mu \mathrm{g} / \mathrm{ml}$ with correlation coefficient of 0.9951 .

\section{In vitro diffusion study}

The in-vitro buccal drug permeation study of buspirone hydrochloride through sheep buccal mucosa was performed using at $37 \pm 0.2^{\circ} \mathrm{C}$, mucosa mounted between the donor and receptor compartments. The buccal tablet was placed with the core facing the membrane and the compartments clamped together. The donor and receptor compartments were filled with phosphate buffer $\mathrm{pH} 6.4$ and the hydrodynamics in the receptor compartment was maintained by stirring with a magnetic bead at $50 \mathrm{rpm}$. One milliliter sample was withdrawn at predetermined time intervals and analyzed for drug content at $239 \mathrm{~nm}$ using UV spectrophotometer

The cumulative amount of permeated drug was plotted versus time and the steady-state flux was calculated using the formula:

$$
\mathrm{J}_{\mathrm{SS}=} \Delta \mathrm{M} /(\mathrm{A} . \Delta \mathrm{t})
$$

Where $\Delta \mathrm{M}$ is the amount of drug transported across the membrane during the time $\Delta \mathrm{t}$ and $\mathrm{A}$ is the diffusional area.

\section{Bio adhesive strength}

A modified balance method was used to determining the ex vivo mucoadhesive strength. Fresh sheep buccal mucosa was obtained from a local slaughterhouse and used within $2 \mathrm{~h}$ of slaughter. The mucosal membrane was separated by removing underlying fat and loose tissues. The membrane was washed with distilled water and then with phosphate buffer $(\mathrm{pH} 6.4)$ at $37^{\circ} \mathrm{C}$. The sheep buccal mucosa was cut into pieces and washed with phosphate buffer ( $\mathrm{pH}$ 6.4). A piece of buccal mucosa was tied to glass slide which was fixed on plank and the plank was assembled with a crown block. After hydrating the mucosa with distilled water, the tablet was brought in contact with the mucosa by applying little force for a minute. After the initial contact, the tablet was encircled by a thread which fastened a light plastic beaker through the crown block. Then, water was dropped into beaker until the tablet and sheep mucosa were pulled apart by the gravity of water. The beaker containing water was weighed and minimum detachment force was calculated accordingly. The experiments were performed and average values with standard deviation were reported. This detachment force gives the mucoadhesive strength of the buccal tablet in grams [22]

Table 1: Composition of buspirone hydrochloride buccal adhesive tablets

\begin{tabular}{llllllllll}
\hline Formulations & F1 & F2 & F3 & F4 & F5 & F6 & F7 & F8 & F9 \\
\hline Drug & 9.40 & 9.40 & 9.40 & 9.40 & 9.40 & 9.40 & 9.40 & 9.40 & 9.40 \\
HPMC K4M & 20 & - & - & - & 10 & - & - & - \\
HPMC K15M & - & 20 & - & - & - & - & - & - & - \\
Gantrez MS-955 & - & - & 20 & - & - & - & - & 10 & 10 \\
Carbopol-934 & - & - & - & 20 & 10 & - & - & - & 10 \\
Sod. CMC & - & - & - & - & - & 20 & - & - & - \\
Sod. Alginate & - & - & - & - & - & - & 20 & - \\
MCC & 14.6 & 14.6 & 14.6 & 14.6 & 14.6 & 14.6 & 14.6 & 14.6 & 14.6 \\
Mannitol & 4 & 4 & 4 & 4 & 4 & 4 & 4 & 4 \\
Mg. Stearate & 1 & 1 & 1 & 1 & 1 & 1 & 1 & 1 \\
Talc & 1 & 1 & 1 & 1 & 1 & 1 & 1 & 1 \\
Ethyl cellulose & 50 & 50 & 50 & 50 & 50 & 50 & 50 & 50 & 1 \\
Color & Sunset yellow & 100 & 100 & 100 & 100 & 100 & 100 & 100 \\
Total weight & 100 & 100 & & & & & & & 100 \\
\hline
\end{tabular}

*All quantities are in mg. Sod. CMC: Sodium carboxymethylcellulose 
Table 2: Factorial design and values of independent variables

\begin{tabular}{|c|c|c|c|c|c|c|}
\hline \multirow[b]{2}{*}{ Formulation code } & \multicolumn{2}{|c|}{ Independent variable } & \multicolumn{4}{|l|}{ Dependent variable } \\
\hline & $X_{1}$ & $\mathbf{X}_{2}$ & $Y_{1}$ (bioadhesion strength dynes) & $Y_{2}(Q 2) \%$ & $Y_{3}(Q 4) \%$ & $Y_{4}(Q 6) \%$ \\
\hline A1 & -1 & -1 & 13.416 & 64.667 & 75.934 & 83.129 \\
\hline A2 & -1 & 0 & 13.634 & 58.547 & 72.570 & 85.517 \\
\hline A3 & -1 & +1 & 13.923 & 55.431 & 74.787 & 87.839 \\
\hline A4 & 0 & -1 & 12.021 & 49.937 & 70.412 & 84.771 \\
\hline A5 & 0 & 0 & 11.385 & 55.124 & 72.232 & 86.683 \\
\hline A6 & 0 & +1 & 13.002 & 49.432 & 71.994 & 89.549 \\
\hline A7 & +1 & -1 & 13.053 & 41.213 & 60.378 & 85.475 \\
\hline A8 & +1 & 0 & 13.669 & 42.215 & 61.231 & 88.523 \\
\hline A9 & +1 & +1 & 13.778 & 45.006 & 65.023 & 93.964 \\
\hline \multicolumn{7}{|c|}{ Translation of coded levels in actual units } \\
\hline \multirow[t]{2}{*}{ Independent variable } & & Real value & & & & \\
\hline & & Low $(-1)$ & Medium (0) & High (+1) & & \\
\hline Carbopol-934 (X1) & & 5 & 7.5 & 10 & & \\
\hline Gantrez MS-955 (X2) & & 10 & 12.5 & 15 & & \\
\hline
\end{tabular}

Table 3: Calibration curve of buspirone hydrochloride

\begin{tabular}{ll}
\hline Concentration $(\mathrm{mcg} / \mathrm{ml})$ & Absorbance $(\mathbf{n m})$ \\
\hline 0 & 0 \\
4 & $0.237 \pm 0.021$ \\
6 & $0.4 \pm 0.025$ \\
8 & $0.571 \pm 0.017$ \\
10 & $0.684 \pm 0.022$ \\
12 & $0.865 \pm 0.011$ \\
\hline
\end{tabular}

Table 4: Evaluation parameter of batches for optimization of mucoadhesive polymers and excipients (trial 1 with lactose)

\begin{tabular}{llll}
\hline $\begin{array}{l}\text { Batch } \\
\text { code }\end{array}$ & $\begin{array}{l}\text { Bioadhesion } \\
\text { strength (dynes) }\end{array}$ & $\begin{array}{l}\text { \% Cumulative } \\
\text { release at 6 h } \mathbf{~ \% )}\end{array}$ & $\begin{array}{l}\text { Drug content } \\
\text { (\%) }\end{array}$ \\
\hline F1 & $6.889 \pm 0.05$ & $61.781 \pm 0.03$ & $97.560 \pm 0.01$ \\
F2 & $6.671 \pm 0.03$ & $55.997 \pm 0.02$ & $99.000 \pm 0.06$ \\
F3 & $3.626 \pm 0.02$ & $61.316 \pm 0.03$ & $98.000 \pm 0.05$ \\
F4 & $14.504 \pm 0.02$ & $57.460 \pm 0.03$ & $98.100 \pm 0.05$ \\
F5 & $8.702 \pm 0.01$ & $57.061 \pm 0.04$ & $97.750 \pm 0.03$ \\
F6 & $7.252 \pm 0.10$ & $57.992 \pm 0.05$ & $98.640 \pm 0.01$ \\
F7 & $10.152 \pm 0.01$ & $68.630 \pm 0.05$ & $98.300 \pm 0.09$ \\
F8 & $5.801 \pm 0.15$ & $64.906 \pm 0.01$ & $97.560 \pm 0.01$ \\
F9 & $8.122 \pm 0.01$ & $67.433 \pm 0.03$ & $99.010 \pm 0.01$ \\
\hline
\end{tabular}

Force of detachment (dynes) = Actual wt for detachment $(\mathrm{g}) \times \mathrm{g}$

Where $\mathrm{g}=$ acceleration due to the gravity $\left(980 \mathrm{~cm} / \mathrm{s}^{2}\right)$

Kinetics of drug release

The in vitro release data of buspirone from different batches of tablets were fitted using the zero-order, first-order, and Higuchi diffusion models as well as the Korsmeyer-Peppas equation to determine the model that best describes drug release from pellet formulations. The preference of the release mechanism is based on the value of the correlation coefficient. The data revealed a good fit to the KorsmeyerPeppas equation, indicating combined effects of diffusion and erosion mechanisms for drug release. In addition, the release exponent (n) was calculated from the Korsmeyer equation.

\section{Stability studies}

The purpose of stability study is to provide evidence on the quality of a drug substance or drug product which varies with time under the influence of a variety of environmental factors such as temperature, humidity, and light. Formulations were selected for stability on the basis

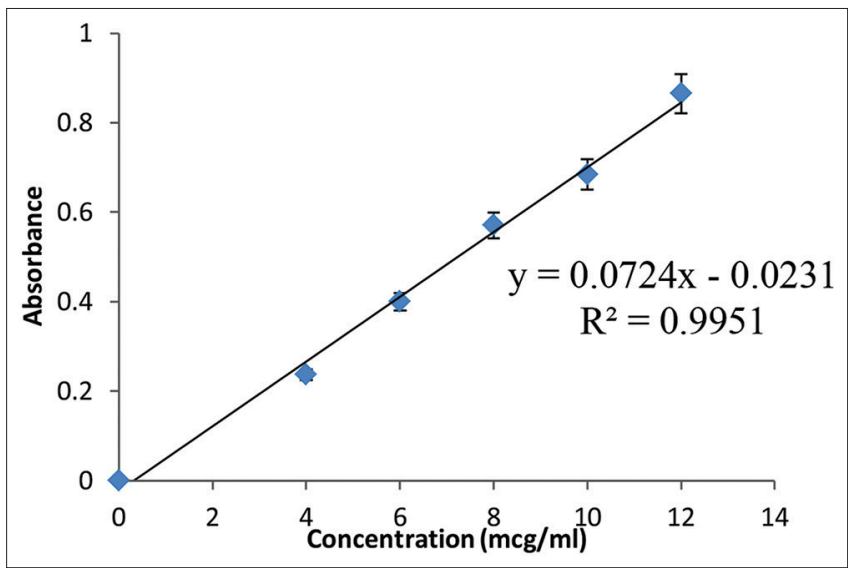

Fig. 1: Calibration curve of buspirone hydrochloride

of the in vitro drug release profile. The formulations were subjected to accelerated stability studies as per ICH guidelines, that is, $40^{\circ} \mathrm{C}$ temperature and $75 \% \mathrm{RH}$ in aluminum foil for 1 month in thermostated ovens. The samples were taken at 0 and 30 days. Tablets were evaluated for the different physicochemical parameters.

\section{RESULTS AND DISCUSSION}

Spectral analysis of buspirone hydrochloride

Determination of $\lambda$ max

The standard solution of concentration $10 \mu \mathrm{g} / \mathrm{ml}$ of buspirone hydrochloride was prepared in $\mathrm{pH} 6.4$ phosphate buffers to obtain the desired concentration and subjected for UV scanning in the range of 200-400 nm using a double beam UV-visible spectrophotometer.

Construction of calibration curve of buspirone hydrochloride

Aliquots of concentrations $4,6,8,10$, and $12 \mu \mathrm{g} / \mathrm{ml}$ were prepared from standard solution with Phosphate buffer $\mathrm{pH}$ 6.4. The absorbance of the prepared solutions was measured at $239 \mathrm{~nm}$ using UV/visible spectrophotometer.

\section{FTIR study}

FTIR spectra of buspirone hydrochloride were found to be similar as that of P203 polymorph. It has strong additional bands in the range of $2600-2400 \mathrm{~cm}^{-1}$, at 1350 and $1450 \mathrm{~cm}^{-1}$ which is absent in P-188 form as per literature. The spectra for Buspirone $\mathrm{HCl}$ is shown in Fig. 2 and Buspirone $\mathrm{HCl}$ with excipients is shown in Fig. 3. 


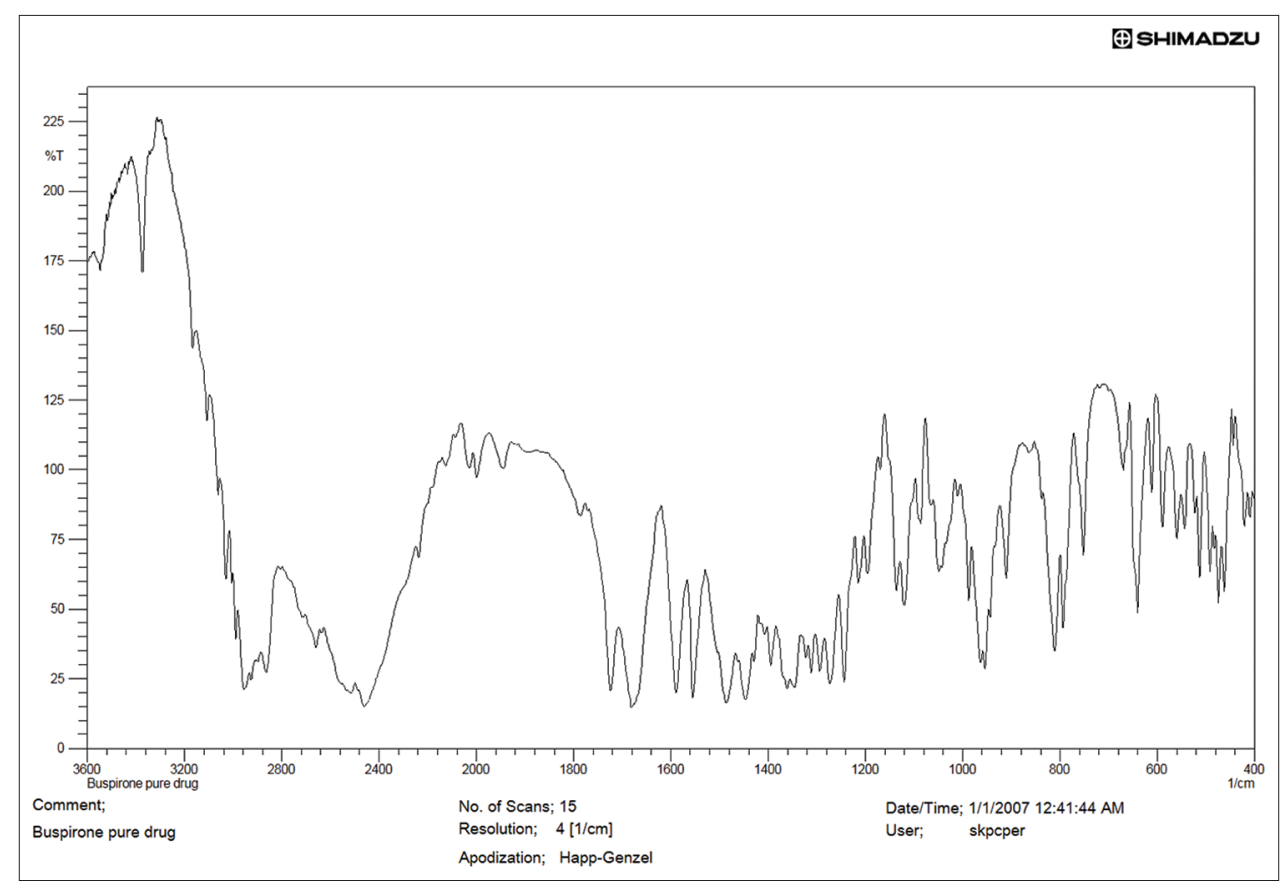

Fig. 2: Fourier-transform infrared of buspirone hydrochloride

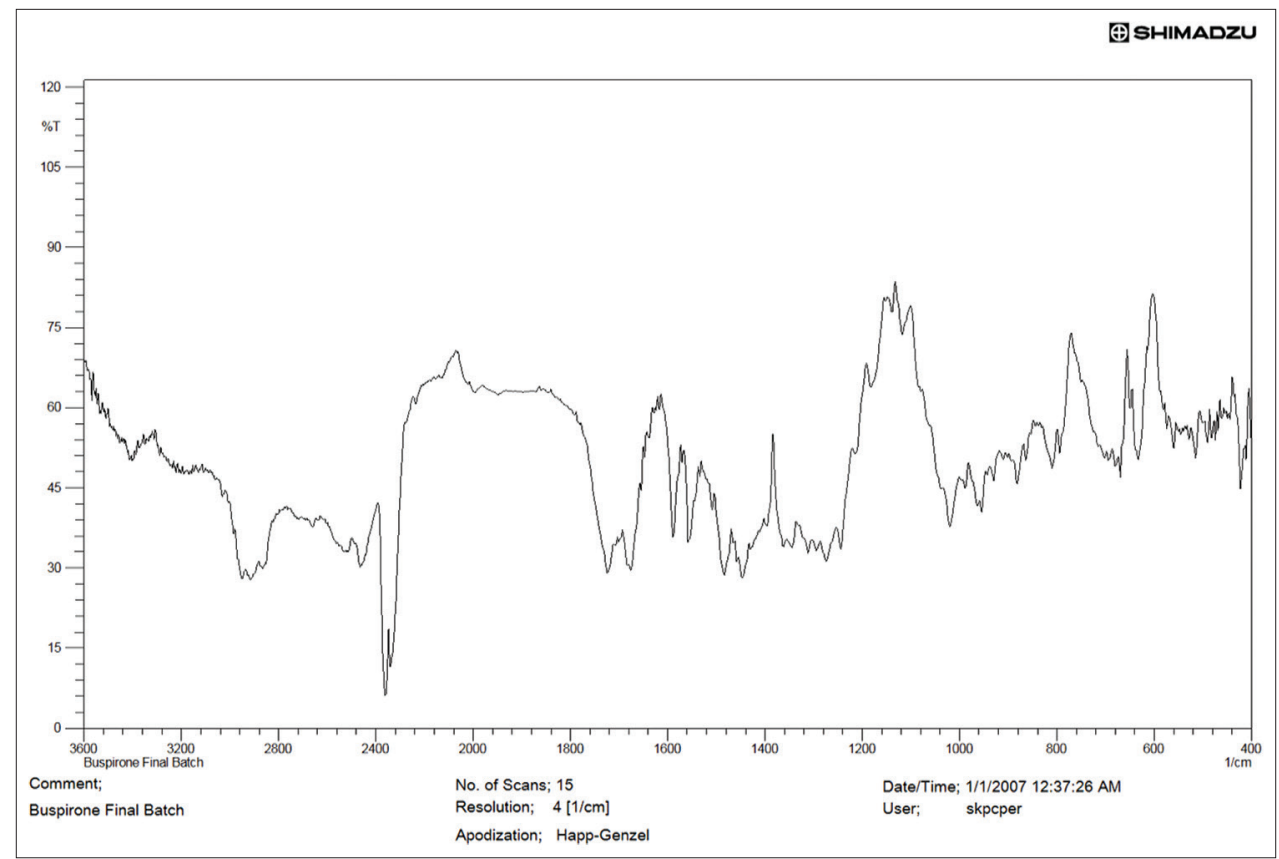

Fig. 3: Fourier-transform infrared of buspirone hydrochloride with excipients

\section{DSC study}

DSC spectra of buspirone $\mathrm{HCl}$ plain drug show an endothermic peak at $205^{\circ} \mathrm{C}$. When the spectra of the mixture were taken there was no change in peak observed which shows that drug and polymers are compatible with each other.

Buspirone $\mathrm{HCl}$ may appear in two polymorphic forms:

- Low melting point form described in P188 described in U.S. Patent $4,810,789$ having a melting point $192^{\circ} \mathrm{C}$ then converted into higher melting polymorph at $205^{\circ} \mathrm{C}$

- Higher melting point form P203 described in U.S. Patent 3,717,634 having a melting point $203-205^{\circ} \mathrm{C}$. It also has strong additional bands in the range of $2600-2400 \mathrm{~cm}^{-1}$, at 1350 and $1450 \mathrm{~cm}^{-1}$.
Optimization of mucoadhesive polymers and excipients

Different batches were prepared to optimize mucoadhesive polymers and other excipients. Various polymers such as HPMC K4M, HPMC K15, Carbopol 934, Gantrez MS 955, sodium alginate, and sodium carboxymethyl cellulose were taken along with the excipients such as mannitol and lactose for optimization.

In this study, an attempt has been made to develop buspirone hydrochloride buccal adhesive tablets to avoid the first-pass metabolism and to increase the bio-availability of the drug. Two prime considerations in the design of buccal adhesive tablets, one is to attach firmly to the buccal mucosa and other in case of buspirone bio-availability of drug (\% drug release). Here, in the preliminary 
study, batch F4, F6, F7, and F9 show the good release of the drug, but when release pattern is considered, it is well observed in batch F7 and F9. In trial-2, with mannitol increase in drug release profile was observed then lactose. Hence, mannitol was selected instead of lactose and when bioadhesive strength and dissolution profile both factors are considered it is well observed in batch F9 and F18 (Carbopol-934 and Gantrez MS-955). Finally, for factorial design Carbopol-934, 5-7.5-10 mg and Gantrez MS-955 10-12.5-15 mg were considered.

\section{Powder blend property}

The micromeritic properties of the powder blend of the formulations were checked, angle of repose was found to be around $19-29^{\circ}$, which shows good to average flowing properties of the powder blend. The loose bulk and tapped density were found around $0.395-0.486$ and $0.504-0.593 \mathrm{~g} / \mathrm{cc}$, respectively. Carr's index was observed between $16.23 \%$ and $23.39 \%$ and Hausner's ratio was between 1.16 and 1.23 . The drug content was found to be between $95.23 \%$ and $99.02 \%$, which passes the official requirement. This ensured the uniformity of the drug content in the tablets. Weight variation data of the prepared tablets indicated no significant difference in the weight of individual tablet from the average value. Hardness and the thickness of the prepared tablets were observed within the range of $3.8-4.2 \mathrm{~kg} / \mathrm{cm}^{2}$ and $1.99-$ $2.2 \mathrm{~mm}$, respectively.

\section{In-vitro dissolution}

Fig. 6 and Table 5 show the in-vitro drug release studies performed for A1-A9 formulations using $\mathrm{pH} 6.4$ phosphate buffers as dissolution medium and measuring drug concentration UV spectrophotometrically at $239 \mathrm{~nm}$. The studies were performed for $6 \mathrm{~h}$

In-vitro bioadhesive strength

Fig. 7 and Table 6 show the result of in-vitro bioadhesive strength of formulated tablets of batches A1-A9 using sheep buccal mucosa.

\section{Statistical analysis of factorial design batches}

The polynomial equations can be used to draw conclusions after considering the magnitude of coefficient and the mathematical sign it carries (positive or negative). Consequently, the equations may be used to obtain estimates of response as a relative small error of variance was noticed in the replicates. The data transformation simplifies the calculations for model development. The data generated by the experimental design were utilized for drawing contour plot, to obtain an optimized region within the factorial space, and thereby produce an optimized formulation.

\section{Effect of variable on bio-adhesion}

\begin{tabular}{lll}
\hline Regression statistics & & \\
\hline Multiple R & 0.934 & \\
R square & 0.874 & \\
Adjusted R square & 0.664 & \\
Standard error & 0.500 & \\
Observations & 9 & \\
\hline Coefficients & & p-value \\
\hline Coefficient & Coefficient value & 0.013 \\
\hline $\mathrm{b}_{0}$ & 11.934 & 0.072 \\
$\mathrm{~b}_{1}$ & -0.079 & 0.016 \\
$\mathrm{~b}_{2}$ & 0.378 & 0.084 \\
$\mathrm{~b}_{11}$ & 1.442 & 0.264 \\
$\mathrm{~b}_{22}$ & 0.302 & 0.452 \\
$\mathrm{~b}_{12}$ & 0.054 & \\
Equation: & & \\
$\mathrm{Y}=11.93-0.079 \mathrm{X}_{1}+0.37 \mathrm{X}_{2}+0.054 \mathrm{X}_{1} \mathrm{X}_{2}+1.44 \mathrm{X}_{1}{ }^{2}+0.30 \mathrm{X}_{2}{ }^{2}$ & \\
\hline
\end{tabular}

Coefficients with one factor represent the effect of that particular factor on responses, while the coefficients with more than one factor and those with second-order terms represent the interaction between

Table 5: Evaluation parameter of batches for optimization of mucoadhesive polymers and excipients (trial 2 with mannitol)

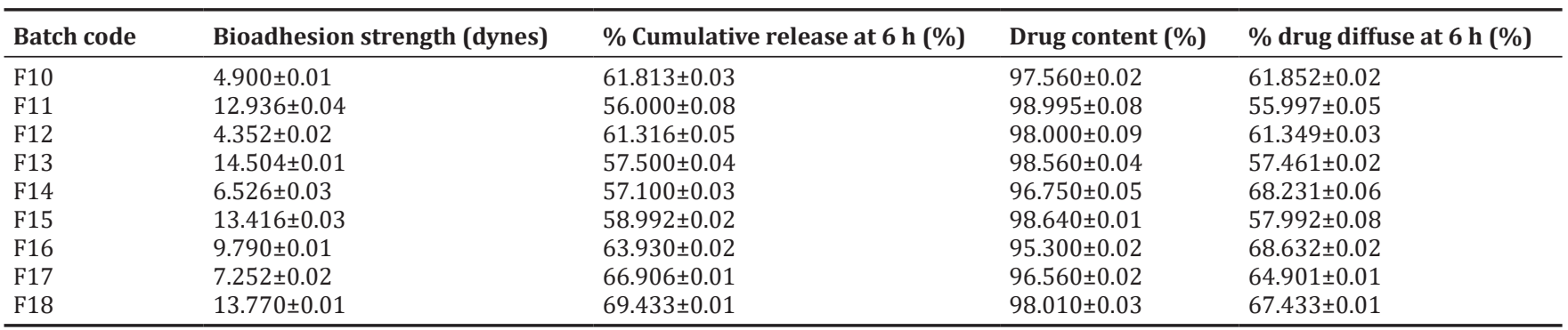

Table 6: Formulation and optimization of buccoadhesive tablets using $3^{2}$ full factorial design

\begin{tabular}{|c|c|c|c|c|c|c|}
\hline \multirow[t]{2}{*}{ Formulation code } & \multicolumn{2}{|c|}{ Independent variable } & \multicolumn{4}{|l|}{ Dependent variable } \\
\hline & $\mathrm{X}_{1}$ & $\mathbf{X}_{2}$ & $Y_{1}$ (Bioadhesion strength dynes) & $Y_{2}(Q 2) \%$ & $Y_{3}(Q 4) \%$ & $Y_{4}(Q 6) \%$ \\
\hline A1 & -1 & -1 & 13.416 & 64.667 & 75.934 & 83.129 \\
\hline A2 & -1 & 0 & 13.634 & 58.547 & 72.570 & 85.517 \\
\hline A3 & -1 & +1 & 13.923 & 55.431 & 74.787 & 87.839 \\
\hline A4 & 0 & -1 & 12.021 & 49.937 & 70.412 & 84.771 \\
\hline A5 & 0 & 0 & 11.385 & 55.124 & 72.232 & 86.683 \\
\hline A6 & 0 & +1 & 13.002 & 49.432 & 71.994 & 89.549 \\
\hline A7 & +1 & -1 & 13.053 & 41.213 & 60.378 & 85.475 \\
\hline A8 & +1 & 0 & 13.669 & 42.215 & 61.231 & 88.523 \\
\hline A9 & +1 & +1 & 13.778 & 45.006 & 65.023 & 93.964 \\
\hline \multicolumn{7}{|c|}{ Translation of coded levels in actual units } \\
\hline \multirow[t]{2}{*}{ Independent variable } & & \multicolumn{5}{|l|}{ Real value } \\
\hline & & Low $(-1)$ & Medium (0) & High (+1) & & \\
\hline Carbopol-934 & & 5 & 7.5 & 10 & & \\
\hline Gantrez MS-955 & & 10 & 12.5 & 15 & & \\
\hline
\end{tabular}




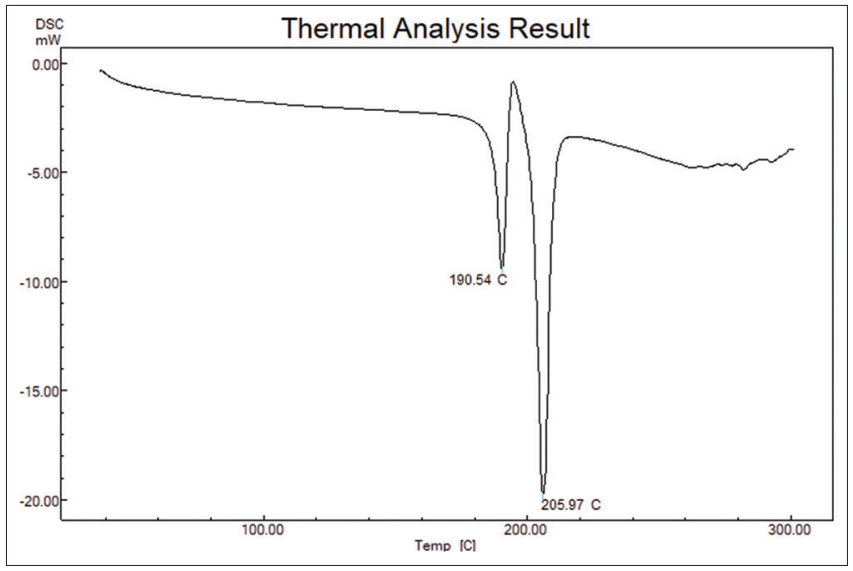

Fig. 4: DSC spectra of pure drug

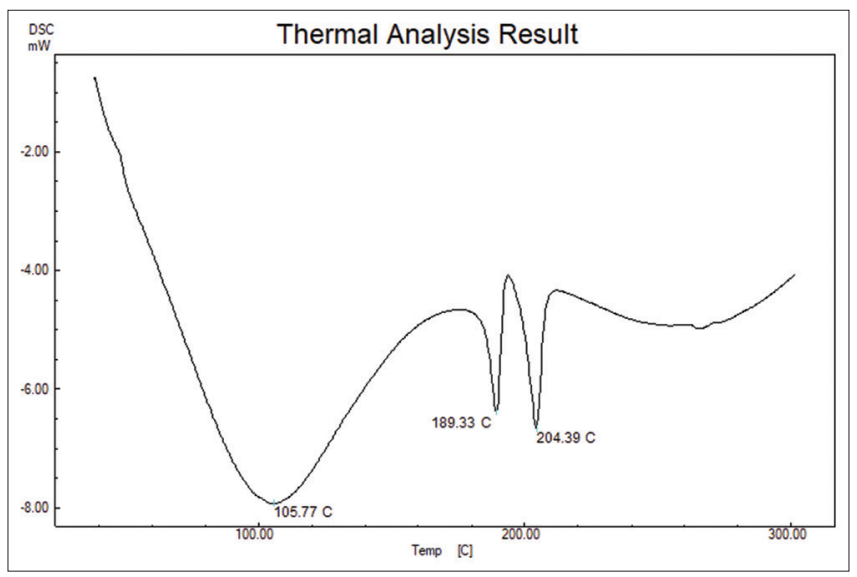

Fig. 5: DSC spectra of mixture those factors and the quadratic nature of the phenomena, respectively. Positive sign in front of the terms indicates a synergistic effect, while a negative sign indicates an antagonistic effect upon the responses. For response Y1 (bio-adhesion) mathematical model was used, omitting the insignificant terms ( $p>0.05$ ) by adopting multiple regression analysis. The effect of X1 and X2 was found significant $(\mathrm{p}<0.05)$.

The high p-value of $X_{1}$ and $X_{2}$ suggests that the interaction between $X_{1}$ and $X_{2}$ is not significant. The combined effect of factors $X_{1}$ and $X_{2}$ can further be elucidated with the help of response surface and counter plots which demonstrate that $\mathrm{Y}_{1}$ varies in a linear fashion with the amount of both polymers.

Effect of variable on \% cumulative release at $2 \mathrm{~h} \mathrm{(Q2)}$

\begin{tabular}{lll}
\hline Regression statistics & & \\
\hline Multiple $\mathrm{R}$ & 0.978 & \\
R Square & 0.956 & \\
Adjusted R square & 0.884 & \\
Standard error & 2.667 & \\
Observations & 9 & \\
\hline Coefficients & & p-value \\
\hline Coefficient & Coefficient value & 0.0001 \\
\hline $\mathrm{b}_{0}$ & 52.173 & 0.004 \\
$\mathrm{~b}_{1}$ & -8.368 & 0.429 \\
$\mathrm{~b}_{2}$ & -0.991 & 0.876 \\
$\mathrm{~b}_{11}$ & -0.317 & 0.628 \\
$\mathrm{~b}_{22}$ & -1.014 & 0.092 \\
$\mathrm{~b}_{12}$ & 3.257 & \\
Equation: & & \\
$\mathrm{Y}=52.173-8.368 \mathrm{X}_{1}-0.991 \mathrm{X}_{2}+3.257 \mathrm{X}_{1} \mathrm{X}_{2}-0.317 \mathrm{X}_{1}{ }^{2}-1.014 \mathrm{X}_{2}{ }^{2}$ \\
\hline
\end{tabular}

The quadratic model for Q2 (release at $2 \mathrm{~h}$ ) was found to be significant with $\mathrm{F}$ value of 13.462 . The variable had a significant effect on $\%$ drug release. A relationship was obtained between the fraction of

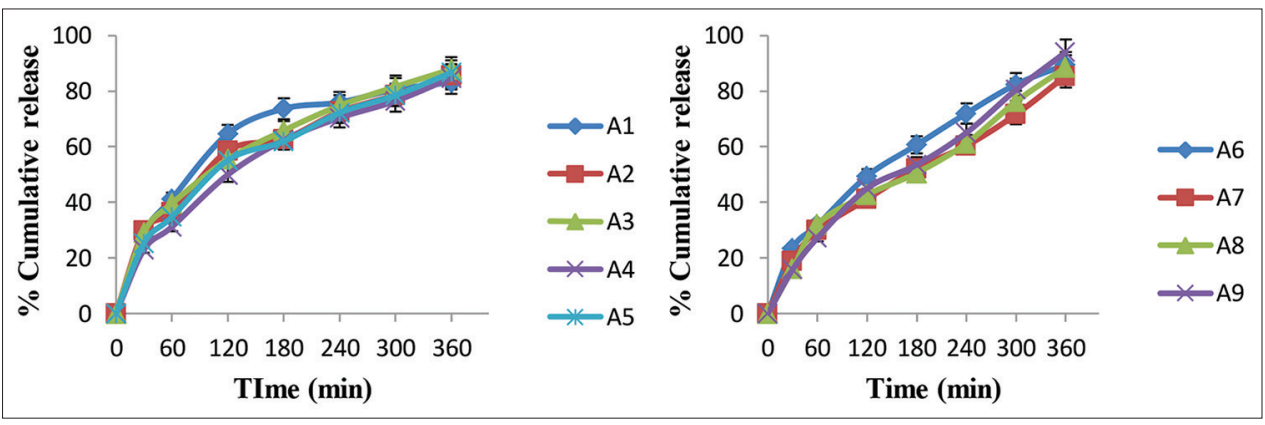

Fig. 6: \% Cumulative release of factorial batches

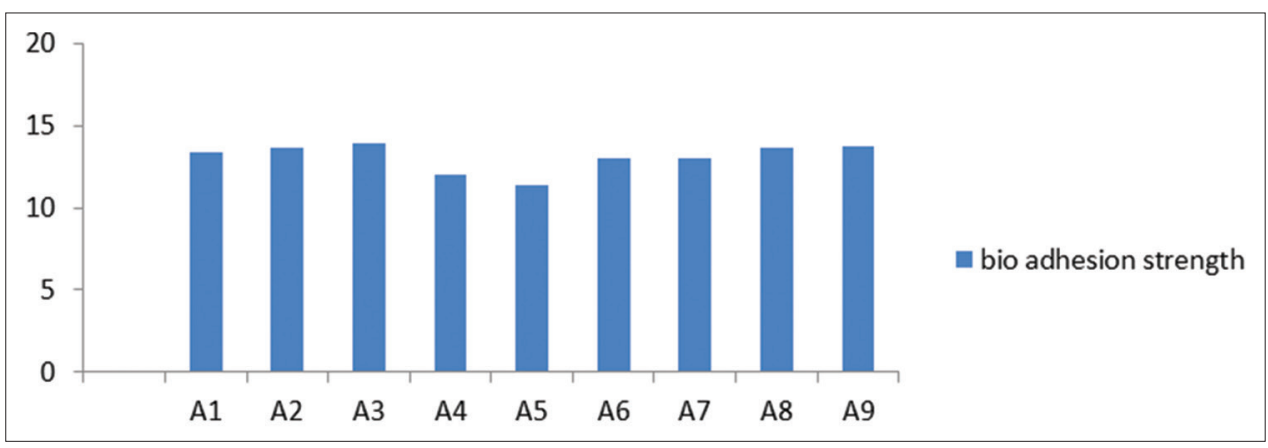

Fig. 7: In-vitro bioadhesion of factorial batches 


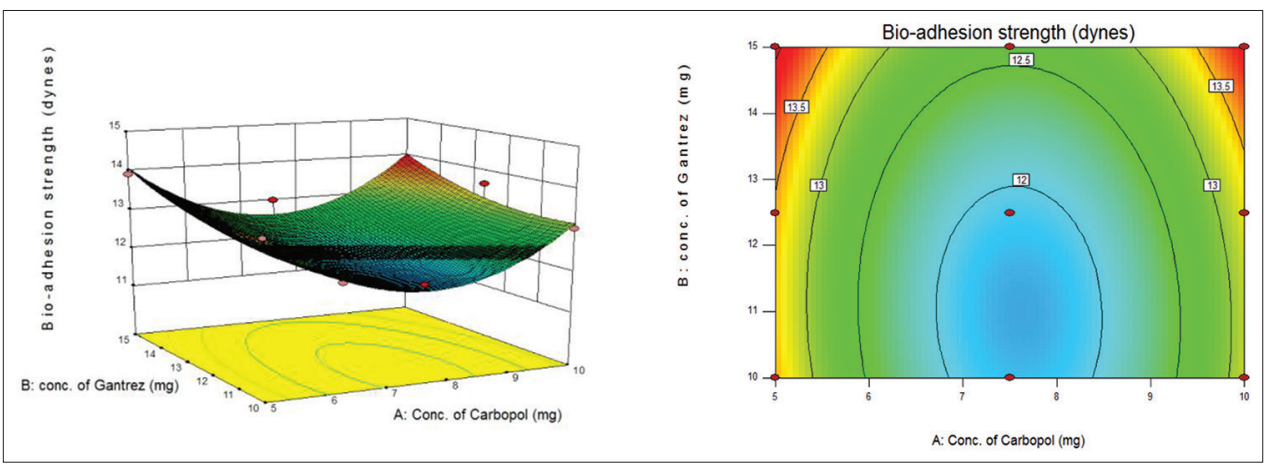

Fig. 8: Counter Plot (3-D) graph of Y1 (bioadhesion strength)

Table 7: Micromeritic properties of powder blends of different batches

\begin{tabular}{|c|c|c|c|c|c|c|}
\hline Batch code & Angle of repose $\left(^{\circ}\right)$ & Bulk density (g/cc) & Tapped density (g/cc) & Carr's index (\%) & Hausner's ratio & Drug content $(\%)$ \\
\hline A1 & $19 \pm 1.05$ & $0.486 \pm 0.01$ & $0.593 \pm 0.12$ & $16.23 \pm 1.20$ & $1.18 \pm 0.18$ & $97.63 \pm 0.01$ \\
\hline $\mathrm{A} 2$ & $25 \pm 1.23$ & $0.432 \pm 0.01$ & $0.504 \pm 0.45$ & $16.46 \pm 1.56$ & $1.20 \pm 0.32$ & $98.09 \pm 0.04$ \\
\hline A3 & $29 \pm 1.85$ & $0.395 \pm 0.06$ & $0.568 \pm 0.39$ & $23.39 \pm 1.88$ & $1.16 \pm 0.24$ & $95.23 \pm 0.02$ \\
\hline A4 & $25 \pm 1.63$ & $0.420 \pm 0.04$ & $0.518 \pm 0.21$ & $18.51 \pm 1.28$ & $1.23 \pm 0.06$ & $98.15 \pm 0.01$ \\
\hline A5 & $21 \pm 1.25$ & $0.490 \pm 0.03$ & $0.598 \pm 0.09$ & $18.04 \pm 1.36$ & $1.13 \pm 0.09$ & $97.00 \pm 0.06$ \\
\hline A6 & $23 \pm 1.29$ & $0.482 \pm 0.02$ & $0.588 \pm 0.33$ & $16.76 \pm 1.43$ & $1.24 \pm 0.85$ & $98.32 \pm 0.03$ \\
\hline A7 & $22 \pm 1.32$ & $0.420 \pm 0.01$ & $0.528 \pm 0.20$ & $13.73 \pm 1.09$ & $1.29 \pm 0.26$ & $95.32 \pm 0.05$ \\
\hline A9 & $20 \pm 1.08$ & $0.497 \pm 0.01$ & $0.521 \pm 0.05$ & $12.90 \pm 1.04$ & $1.03 \pm 0.05$ & $99.02 \pm 0.01$ \\
\hline
\end{tabular}

Table 8: Evaluation of buccoadhesive tablets for buspirone hydrochloride

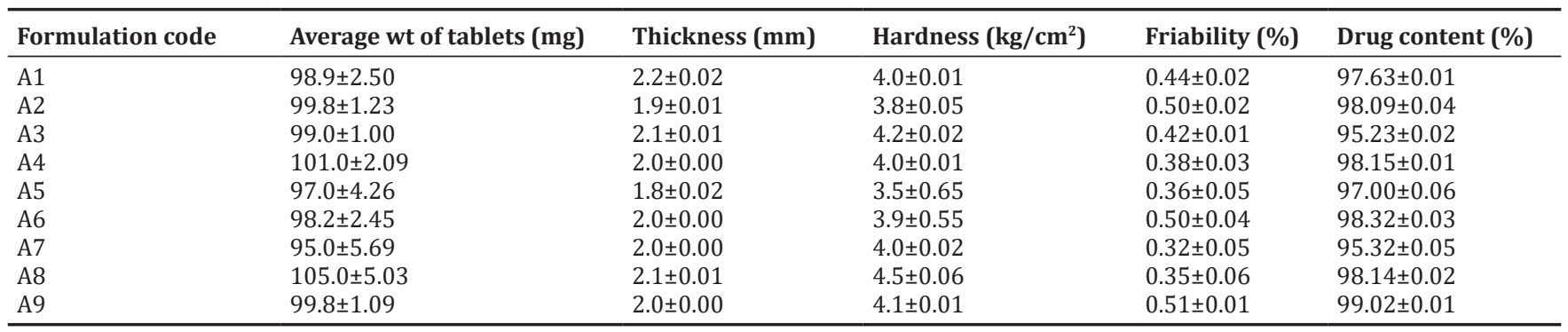

Table 9: \% Cumulative release of factorial batches

\begin{tabular}{|c|c|c|c|c|c|c|c|c|c|}
\hline Time (Min.) & A1 & A2 & A3 & A4 & A5 & A6 & A7 & A8 & A9 \\
\hline 0 & 0.00 & 0.00 & 0.00 & 0.00 & 0.00 & 0.00 & 0.00 & 0.00 & 0.00 \\
\hline 30 & $28.83 \pm 0.08$ & $29.89 \pm 0.05$ & $29.07 \pm 0.02$ & $22.98 \pm 0.02$ & $25.37 \pm 0.02$ & $23.36 \pm 0.04$ & $18.9 \pm 0.18$ & $16.09 \pm 0.03$ & $15.85 \pm 0.08$ \\
\hline 60 & $41.29 \pm 0.03$ & $36.40 \pm 0.08$ & $39.54 \pm 0.04$ & $31.20 \pm 0.3$ & $34.74 \pm 0.08$ & $31.80 \pm 0.04$ & $29.93 \pm 0.09$ & $32.13 \pm 0.01$ & $27.22 \pm 0.06$ \\
\hline 120 & $66.6 \pm 0.05$ & $58.5 \pm 0.05$ & $55.43 \pm 0.69$ & $49.93 \pm 0.05$ & $55.12 \pm 0.06$ & $49.43 \pm 0.03$ & $41.21 \pm 0.25$ & $42.77 \pm 0.03$ & $45.00 \pm 0.01$ \\
\hline 180 & $73.68 \pm 0.07$ & $62.68 \pm 0.36$ & $65.80 \pm 0.03$ & $62.32 \pm 0.06$ & $61.94 \pm 0.08$ & $60.68 \pm 0.02$ & $52.21 \pm 0.06$ & $50.58 \pm 0.03$ & $53.51 \pm 0.02$ \\
\hline 240 & $75.93 \pm 0.06$ & $72.5 \pm 0.25$ & $74.78 \pm 0.09$ & $70.41 \pm 0.03$ & $72.23 \pm 0.02$ & $71.99 \pm 0.01$ & $60.37 \pm 0.03$ & $61.23 \pm 0.02$ & $65.02 \pm 0.01$ \\
\hline 300 & $80.50 \pm 0.09$ & $78.60 \pm 0.07$ & $81.55 \pm 0.01$ & $76.43 \pm 0.01$ & $78.49 \pm 0.06$ & $82.41 \pm 0.05$ & $71.66 \pm 0.03$ & $76.22 \pm 0.02$ & $80.50 \pm 0.06$ \\
\hline
\end{tabular}

Table 10: In-vitro bioadhesive strength

\begin{tabular}{ll}
\hline Formulation & Force for detachment (dyne) \\
\hline A1 & 13.416 \\
A2 & 13.634 \\
A3 & 13.923 \\
A4 & 12.021 \\
A5 & 11.385 \\
A6 & 13.002 \\
A7 & 13.053 \\
A8 & 13.669 \\
A9 & 13.778 \\
\hline
\end{tabular}

Table 11: Coefficients and their p-values

\begin{tabular}{lllll}
\hline Coefficients & $\begin{array}{l}\text { Y1 (bioadhesion } \\
\text { strength) }\end{array}$ & Y2 (Q2) & Y3 (Q4) & Y4 (Q6) \\
\hline Bo & 0.013 & 0.0001 & 0.008 & 0.009 \\
b1 & 0.072 & 0.004 & 0.001 & 0.007 \\
b2 & 0.016 & 0.429 & 0.207 & 0.0021 \\
b11 & 0.084 & 0.876 & 0.324 & 0.490 \\
b22 & 0.264 & 0.628 & 0.038 & 0.369 \\
b12 & 0.452 & 0.092 & 0.111 & 0.082 \\
\hline
\end{tabular}

Carbopol-934 and Gantrez MS 955, and it was observed that \% drug release increase with an increase in the amount of both the polymers. 


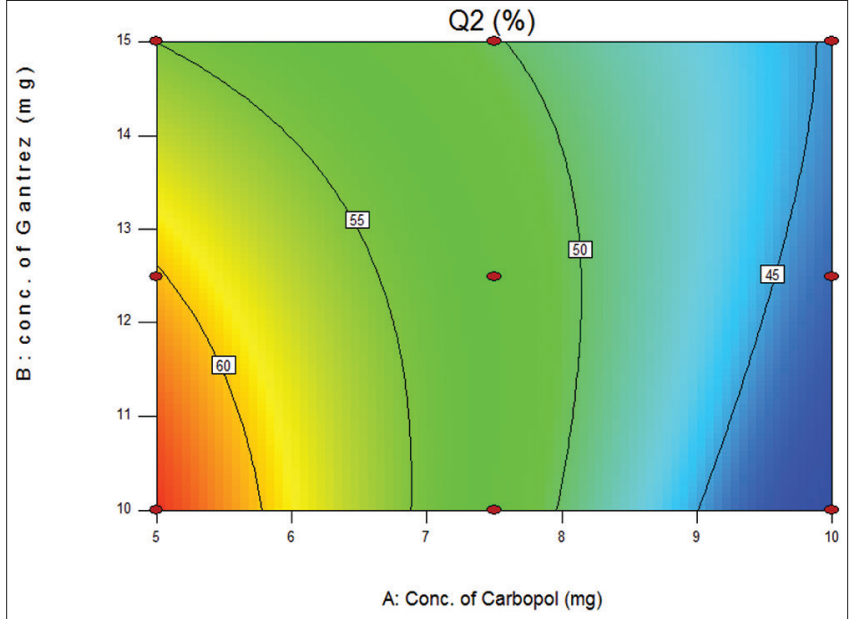

Fig. 9: Surface response graph of Y2 (Q2)
This effect was seen in the drug release at all three points (Q2, Q4, and Q6).

Effect of variable on \% cumulative release at $4 \mathrm{~h}(\mathrm{Q} 4)$

\begin{tabular}{lll}
\hline \multicolumn{2}{l}{ Regression statistics } & \\
\hline Multiple R & 0.978 & \\
R Square & 0.956 & \\
Adjusted R square & 0.884 & \\
Standard error & 2.667 & \\
Observations & 9 & p-value \\
\hline Coefficients & & 0.008 \\
\hline Coefficient & Coefficient value & 0.001 \\
\hline $\mathrm{b}_{0}$ & 70.830 & 0.207 \\
$\mathrm{~b}_{1}$ & -6.110 & 0.324 \\
$\mathrm{~b}_{2}$ & 0.850 & 0.038 \\
$\mathrm{~b}_{11}$ & -3.230 & 0.111 \\
$\mathrm{~b}_{22}$ & 1.080 & \\
Equation: & 1.450 & \\
$\mathrm{Y}=70.830-6.110 \mathrm{X}_{1}+0.850 \mathrm{X}_{2}+1.450 \mathrm{X}_{1} \mathrm{X}_{2}-3.230 \mathrm{X}_{1}{ }^{2}+1.080 \mathrm{X}_{2}{ }^{2}$ \\
\hline
\end{tabular}

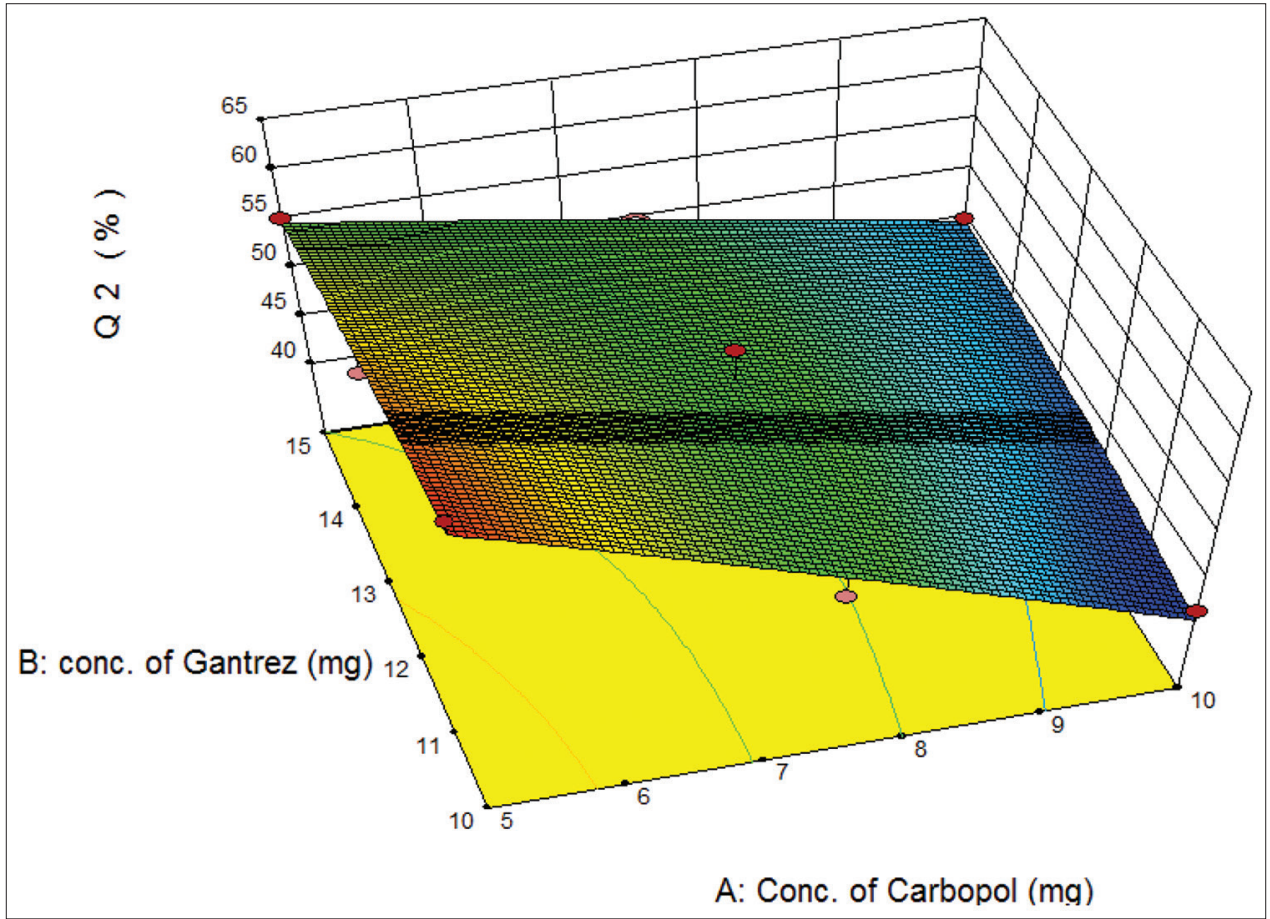

Fig. 10: Counter plot (3-D) graph of Y2 (Q2)

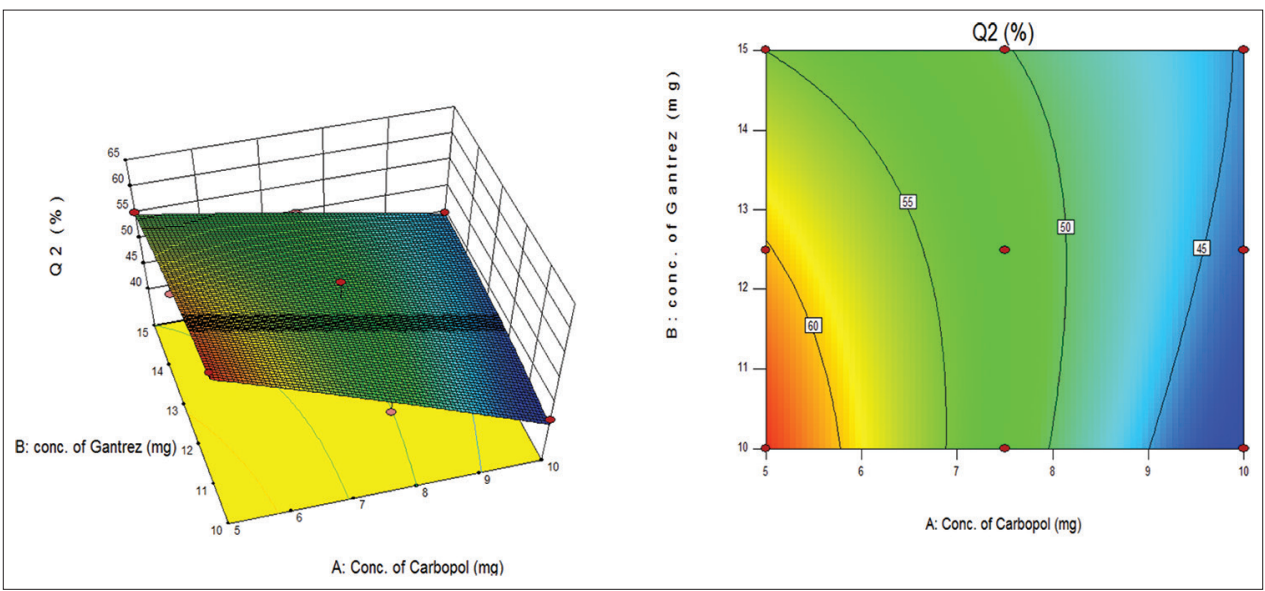

Fig. 11: Counter plot (3-D) graph of Y2 (release at $2 \mathrm{~h}$ [Q2]) 
Effect of variable on \% cumulative release at $6 \mathrm{~h}$ (Q6)

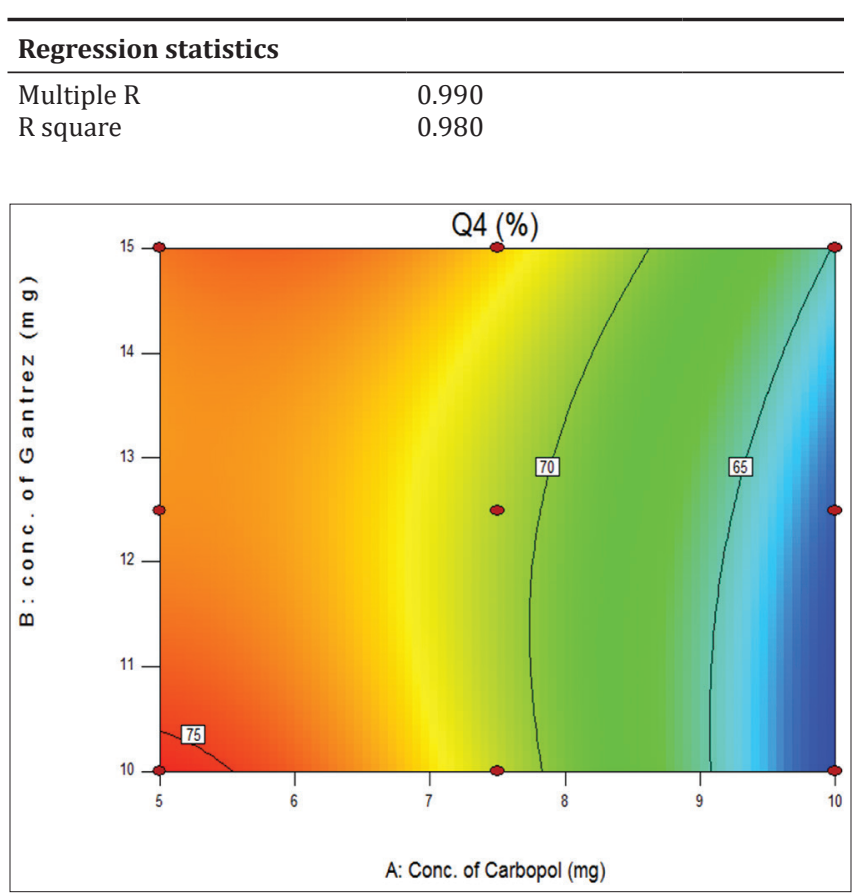

Fig. 12: Counter plot (3-D) graph of Y3 (release at $4 \mathrm{~h} \mathrm{Q4)}$

\begin{tabular}{|c|c|c|}
\hline $\begin{array}{l}\text { Adjusted R square } \\
\text { Standard error } \\
\text { Observations }\end{array}$ & $\begin{array}{l}0.947 \\
0.733 \\
9\end{array}$ & \\
\hline \multicolumn{3}{|l|}{ Coefficients } \\
\hline Coefficient & Coefficient value & P-value \\
\hline $\begin{array}{l}\mathrm{b}_{0} \\
\mathrm{~b}_{1} \\
\mathrm{~b}_{2} \\
\mathrm{~b}_{11} \\
\mathrm{~b}_{22} \\
\mathrm{~b}_{12} \\
\text { Equation: } \\
Y=86.640+1.910 \mathrm{X}_{1}\end{array}$ & $\begin{array}{l}86.640 \\
1.910 \\
3.000 \\
0.410 \\
0.550 \\
0.940 \\
\\
0 \mathrm{X}_{1} \mathrm{X}_{2}+0.410 \mathrm{X}_{1}^{2}+0.5\end{array}$ & $\begin{array}{l}0.009 \\
0.007 \\
0.0021 \\
0.490 \\
0.369 \\
0.082 \\
X_{2}^{2}\end{array}$ \\
\hline
\end{tabular}

The p-value shows that $\mathrm{X} 1$ and $\mathrm{X} 2$ variables, that is, concentration of Carbopol 934 and Gantrez MS 955, respectively, were significantly affecting the Q2, Q6, and Q10 values.

\section{Selection of optimized batch}

A numerical optimization technique by the desirability approach was used to generate the optimum settings for the formulation. The process was optimized for the dependent variables Y1, Y2, Y3, and Y4 arrived at by keeping the bioadhesion force greater than 11.462 dynes $/ \mathrm{cm}^{2}$ and \% drug release Q6 between 84\% and 95\%. The formulation batch A9 fulfilled all the criteria set from the desirability search. To gain say desirability of the response surface model, a new optimized formulation was prepared according to the predicted model and evaluated for the

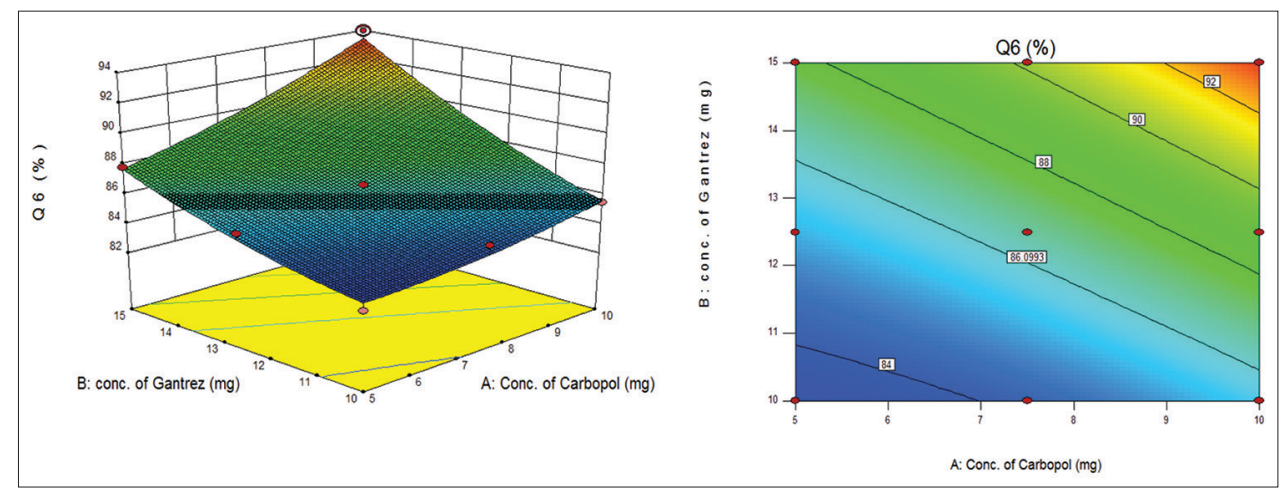

Fig. 13: Counter plot (3-d) graph of Y4 (release at $6 \mathrm{~h}$ Q6)

Table 12: Selection of optimized batch

\begin{tabular}{|c|c|c|c|c|}
\hline & Y1 (bio-adhesion) & Y2 (Q2) & Y3 (Q4) & Y4 (Q6) \\
\hline Predicted & 14.18 & 44.62 & 67.37 & 98.23 \\
\hline Observed & 13.98 & 46.50 & 68.02 & 94.96 \\
\hline Predicted error & 1.40 & 3.48 & 0.96 & 3.32 \\
\hline
\end{tabular}

Predicted error $(\%)=$ (observed value-predicted value $) /$ predicted value $\times 100 \%$

Table 13: Dissolution kinetic model data of buspirone HCL

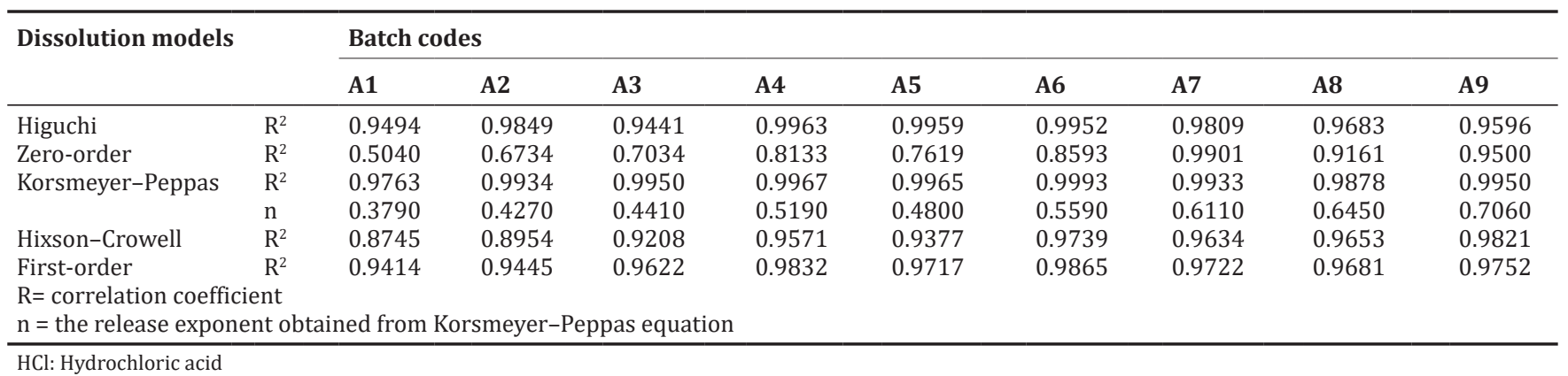


Table 14: Stability study parameters for optimized batch

\begin{tabular}{lll}
\hline Parameters & \multicolumn{2}{l}{ Time (days) } \\
\cline { 2 - 3 } & 0 day & $\mathbf{3 0}$ days \\
\hline \% Drug content & $98.23 \pm 0.01$ & $97.65 \pm 0.02$ \\
Bioadhesive strength $\left(\right.$ dynes $/ \mathrm{cm}^{2)}$ & 13.77 & 12.62 \\
\% Drug release (after $6 \mathrm{~h})$ & $93.964 \pm 0.02$ & $93.562 \pm 0.02$ \\
\hline
\end{tabular}

responses. Predicted value and observed values are illustrated in the table below which shows good relationship between the observed and predicted values.

\section{Kinetics of drug release}

The in vitro release data of buspirone from different batches of tablets were fitted using the zero-order, first-order, and Higuchi diffusion models [23] as well as the Korsmeyer-Peppas equation to determine the model that best describes drug release from pellet formulations. Preference of the release mechanism is based on the value of the correlation coefficient. The data revealed a good fit to the KorsmeyerPeppas equation, indicating combined effects of diffusion and erosion mechanisms for drug release. In addition, the release exponent (n) was calculated from the Korsmeyer equation [24-26].

The calculated values of $n$ indicated are more than 0.45 and $<0.89$ in Korsmeyer-Peppas model; means it follows Anomalous (non-Fickian) diffusion. R2 value was nearer to 0.9821 in Hixson-Crowell model in optimized batch which means it follows Hixson-Crowell model of dissolution kinetic models [27]. Release mechanism from polymer follows Hixson-Crowell up to an extent.

\section{Stability study}

After 30 days of stability of the optimized batch, values of all parameters like \% drug content, bioadhesive strength, and were almost similar to the initial values as seen in Table 3 . The result also showed that there is no change in tablet shape and color. The drug dissolution and diffusion profile were just the same of the initial profile (Fig. 5). There was not any significant change in any value, so the formulation is stable. This study is in agreement with the ICH guideline Q1A (R2), that is, no significant change (5\%) [28].

\section{CONCLUSION}

The study suggests that the hydrophilic bioadhesive tablets of buspirone $\mathrm{HCl}$ can be designed using Carbopol 934 and Gantrez MS 955. The matrices demonstrated adequate bioadhesion with buccal mucosa. Moreover, in-vitro bioadhesive strength versus time measurements demonstrated that the combination of two polymers possessed excellent mucoadhesive properties allowing ease of application and removal of the tablets from the buccal mucosa. The mechanism of bioadhesion may potentially result from the interpenetration and physical entanglement of Gantrez with mucus layer. The rate of release of the drug substance as well as the bioadhesive bond strength of the formulation can be modulated by varying the amount of Gantrez and Carbopol included in the tablets. The mucoadhesive buccal tablets evaluated in the present study were easy to formulate, inexpensive, provide easy application, and convenient removal from the mucosal surface and did not irreversible damage the underlying tissue. Therefore, such tablets containing polyacrylic acid bioadhesive polymers along with carbomers may represent an improved buccal delivery system for a variety watersoluble, low molecular weight drugs.

\section{ACKNOWLEDGMENT}

I am thankful to the Department of Industrial Pharmacy and Pharmaceutics, Shree S. K. Patel pharmaceutical College of Education and Research, Ganpat University, Kherva, for their approval and permission in collecting the data and carrying out this study smoothly.

\section{AUTHORS' CONTRIBUTIONS}

All the authors contributed to the preparation of the final manuscript.

\section{CONFLICTS OF INTEREST}

There are no conflicts of interest regarding the publication of this article.

\section{AUTHORS' FUNDING}

The authors did not receive any funding for this research work.

\section{REFERENCES}

1. Fatma AI, Noha AN, Boraie NA, Mortada LM. Mucoadhesive buccal patches of miconazole nitrate, in-vitro/ in-vivo performance and effect of aging. Int J Pharm 2003;264:1-14.

2. Pankil AG, Patel MR, Patel KR, Patel NM. A review article on mucoadhesive buccal drug delivery system. Int J Pharm Res Dev 2011;3:159-73.

3. Gandhi SD, Priyanka RP, Rahul U, Tambawala T, Shah MA. Mucoadhesive drug delivery systems an unusual maneuver for site specific drug delivery system. Int J Pharm Sci 2011;3:851-71.

4. Jain NK. Controlled and Novel Drug Delivery. $1^{\text {st }}$ ed. New Delhi: CBS Publishers and Distributors; 1997. p. 52-81.

5. Patel KV, Patel ND, Dodiya HD, Shelat PK. Buccal bioadhesive drug delivery system, an overview. Ind J Pharm Bio Arch 2011;2:600-9.

6. Shojaei AH. A systemic drug delivery via the buccal mucosal route. Pharm Tech 2001;25:70-81.

7. Tripathi KD. Essential of Medical Pharmacology. $6^{\text {th }}$ ed. New Delhi: Jaypee Brothers Medical Publishers (P) Ltd.; 2008. p. 171-2, 435,465-8.

8. Availble from: https://www.drugbank.ca/drugs/DB00490. [Last accessed on Dec 2013 6]

9. Raymond CR, Paul JS, Owen SC. Handbook of Pharmaceutical Excipients. $5^{\text {th }}$ ed . London, United Kingdom: Pharmaceutical Press; 2009.

10. Nazila SM, Montakarn C, Thomas PJ. The use of mucoadhesive polymers in buccal drug delivery. Adv Drug Deliv Rev 2005;57:1666-91.

11. Lee VH, Robinson JR. Sustained and Controlled Release Drug Delivery System. New York: Marcel Dekker; 2009. 71-121, 138-71.

12. Ahlneck C, Zografi G. The molecular Basis of moisture effects on the physical and chemical stability of drugs in the solid state. Int J Pharm 1990;62:87-95.

13. Chatwal G, Anand. S. Instrumental methods of chemical analysis. In: Analytical Chemistry. $5^{\text {th }}$ ed., Vol. 82. Karnataka: Himalaya Publishing House; 2002. p. 29-30.

14. Silverstein RM, Bassler GC, Morrill TC. Spectrometric Identification of Organic Compounds. $4^{\text {th }}$ ed. New York: John Wiley and Sons, Inc.; 1981.p. 95.

15. Bellamy LJ. In the Infrared Spectra of Complex Organic Molecules. $2^{\text {nd }}$ ed. New York: John Wiley and Sons, Inc.; 1958. p. 1.

16. Adnan A, Lina N, omari A. Pantoprazole sodium. In: Analytical Profile of Drug Substances and Excipients. Vol. 29. Amsterdam, Netherlands: Elsevier; 2005. p. 213-57.

17. Mills T, Roberson JC, Simon MJ. Instrumental Data for Drug Analysis. $3^{\text {rd }}$ ed., Vol. 2. Milton Park, Abingdon-on-Thames: Taylor and Fransis; 2009. p. 1362-3.

18. Prasad RY, Krishnaiah R, Satyanarayana S. In vitro evaluation of guar gum as a carrier for colon specific drug delivery. J Control Rel 1998;51:281-7.

19. Jurairat N, Kampanart H, Satit P. Development of time pH, and enzymecontrolled colonic drug delivery using spray-dried chitosan acetate and hydroxypropyl methylcellulose. Eur J Pharm Biopharm 2008;68:253-9.

20. European Medicines Agency. ICH Topic Q 3 C (R3) Impurities: Residual Solvents, Note For Guidance on Impurities: Residual Solvents (CPMP/ICH/283/95), March 1998 CPMP/ICH/283/95. Amsterdam, Netherlands: European Medicines Agency; 1998.

21. Raval JA, Modi SV, Shah NP. Formulation and process optimization of buccoadhesive tablet of rabeprazole. Int $\mathrm{J}$ Pharm Chem Sci 2012; $1: 277-86$.

22. Udgirkar DB, Hiremath SN, Rao KS, Pawar D. Buccoadhesive tablets containing ketoconazole inclusion complex with $\beta$ - cyclodextrin. Res J Pharm Tech 2009;4:396-404.

23. Higuchi T. Mechanism of sustained action medication: Theoretical analysis of rate of release of solid drugs dispersed in solid matrices. J Pharm Sci 1963;52:1145-9. 
24. Korsmeyer R, Gurny R, Peppas N. Mechanisms of solute release from porous hydrophilic polymers. Int J Pharm 1983;15:25-35.

25. Peppas NA. Analysis of fickian and non-fickian drug release from polymers. Pharm Acta Helv 1985;60:110-1

26. Harland RS, Gazzaniga A, Sangalli ME. Drug/polymer matrix: Swelling and dissolution. Pharm Res 1988;5:488-94.
27. Hixon AW, Crowell JH. Dependence of reaction velocity upon surface and agitation. Ind Eng Chem 1931;23:923-31.

28. ICH Harmonised Tripartite Guideline: Stability Testing of New Drug Drug Substances and Products Q1A(R2) Current Step 4 Version; 2003. Available from: https:/www.ema.europa.eu/en/documents/scientificguideline/ich-q-1-r2-stabilitytesting. 